\title{
Skidding of Motor-Cars
}

$\mathrm{I}^{\mathrm{N}}$ a paper in Roads and Streets of December, Prof. R. A. Moyer gives some interesting results of experiments on skidding tests at various speeds obtained under all kinds of weather conditions. $\mathrm{He}$ finds that all surfaces, except gravel and cinders, increase in slipperiness with an increase in speed. The great majority of skidding accidents occur with wet or icy or snow-covered roads. He says that in no circumstances should a driver with chains go at more than 30 miles an hour on icy rural highways, or at more than fifteen miles an hour on city streets. To prevent skids, the roads should be sprinkled with sand or cinders treated with calcium chloride. The salt hastens the process of embedding the gritty material into the ice. Snow is not nearly so dangerous as ice from the point of view of skidding, but mudcovered pavements can be as dangerous as ice-covered pavements.

At speeds greater than 15 miles an hour, tyres with treads worn smooth are more slippery on wet surfaces than tyres with a non-skid tread design. An overload on lorry tyres lessens the resistance to skidding. Tyres should be kept at a pressure slightly above the recommended minimum. From the point of view of skidding, over and under inflation are equally bad; but faulty brakes and the improper use of brakes are the cause of more skidding accidents than any other driving operation.

If brakes produce a greater retarding effect on one side of a car than on the other, the tendency to skid is very great. Of 2,134 cars tested for un. equalised brakes, 31 per cent had brakes which pro. duced not less than 40 per cent more braking effect on one side than the other, and practically half the cars tested had faulty and inadequate brakes.

In driving round curves there is only one speed at which the centrifugal is exactly balanced by the gravity force. A car going slower than this tends to slide down the banked section, and going faster it tends to move upwards. When a certain critical speed is exceeded, the necessary friction to keep the car on the curve suddenly vanishes, with the result that the car starts to skid. Many drivers from force of habit put on the brakes when the car starts to skid, the usual effect being to make it worse. The majority of accidents on curves are caused by entering the curve at an excessive speed.

Rough spots or waviness on road surfaces greatly reduce the available friction as the speed is increased. Sir Malcolm Campbell proved that a variation of only two inches in 100 feet, which could not be detected by the eye, was sufficient to lift his six ton car off the surface at speeds of about 250 miles per hour. Campbell is the only man who has driven at a speed of more than 200 miles per hour on a straight track, 500 feet wide, without losing control of his car. Prof. Moyer says that the high-speed runs of Campbell, although the factor of safety was low, are important, since they represent the ultimate possibilities in speed under ideal conditions.

\section{Systematic Anatomy of Timber-Producing Trees}

\begin{abstract}
A
REPORT of the committee for the investigation of the systematic anatomy of timber-producing trees (Prof. H. S. Holden, chairman; Dr. Helen Bancroft, secretary ; Prof. J. H. Priestley) was presented to Section K (Botany) at the recent meeting at Norwich of the British Association. Four papers dealing with the Monotoideæ and with British elms have been published, whilst three others on the Monotoideæ, Marquesia acuminata from Northern Rhodesia, and the Dipterocarps in Africa will appear shortly. A brief summary of the report shows the value of the investigation work being carried out from both the scientific and economic points of view. It is stated that continued work on the Monotoidex supports the view, expressed in last year's report, that the members of the group are closely related to one another and, as a whole, to the Dipterocarpaceæ rather than to the Tiliaceæ; and that the timbers can be of little value economically outside the areas where they occur naturally.

New material from Nigeria, regarded in conjunction with the fossil Dipterocarps from Mount Elgon (described in detail in Amer. J. Bot., 22, 164; 1935), indicates very interesting possibilities with
\end{abstract}

regard to the previous history of the Dipterocarps in Africa.

In connexion with research in Great Britain, the work on the vexed question of the elms has indicated that the genus is in a highly variable and plastic condition, and that hybridisation has taken place freely among the British species. A considerable amount of field-work outside the British area has also been carried out in this connexion. The timbers of the different species and hybrids vary greatly in their value from the utilisation point of view ; and a thorough systematic investigation of those types which produce easily worked timber is desirable.

The papers to which the report refers have ap. peared, or are to appear, in such varied publications as the Kew Bulletin, American Journal of Botany, Gardeners' Chronicle, Quarterly Journal of Forestry and the Empire Forestry Journal.

Valuable as this report may be, regarded from its purely botanical aspects, to those interested in the economic side of forestry the practical nature of the potential possibilities of this line of investigation into the systematic anatomy of timber-producing trees will be obvious. 